\title{
Twinfilin 2 Regulates Actin Filament Lengths in Cochlear Stereocilia
}

\author{
Anthony W. Peng, ${ }^{1,2}$ Inna A. Belyantseva, ${ }^{3}$ Patrick D. Hsu, ${ }^{1}$ Thomas B. Friedman, ${ }^{3}$ and Stefan Heller ${ }^{1}$ \\ ${ }^{1}$ Departments of Otolaryngology-Head \& Neck Surgery and Molecular \& Cellular Physiology, Stanford University School of Medicine, Stanford, California \\ 94305, ${ }^{2}$ Speech \& Hearing Biosciences \& Technology-Health Sciences \& Technology, Massachusetts Institute of Technology, Cambridge, Massachusetts \\ 02139, and ${ }^{3}$ Laboratory of Molecular Genetics, Section on Human Genetics, National Institute on Deafness and Other Communication Disorders-National \\ Institutes of Health, Rockville, Maryland 20850
}

Inner ear sensory hair cells convert mechanical stimuli into electrical signals. This conversion happens in the exquisitely mechanosensitive hair bundle that protrudes from the cell's apical surface. In mammals, cochlear hair bundles are composed of 50-100 actin-filled stereocilia, which are organized in three rows in a staircase manner. Stereocilia actin filaments are uniformly oriented with their barbed ends toward stereocilia tips. During development, the actin core of each stereocilium undergoes elongation due to addition of actin monomers to the barbed ends of the filaments. Here we show that in the mouse cochlea the barbed end capping protein twinfilin 2 is present at the tips of middle and short rows of stereocilia from postnatal day 5 (P5) onward, which correlates with a time period when these rows stop growing. The tall stereocilia rows, which do not display twinfilin 2 at their tips, continue to elongate between P5 and P15. When we expressed twinfilin 2 in LLC/PK1-CL4 (CL4) cells, we observed a reduction of espin-induced microvilli length, pointing to a potent function of twinfilin 2 in suppressing the elongation of actin filaments. Overexpression of twinfilin 2 in cochlear inner hair cells resulted in a significant reduction of stereocilia length. Our results suggest that twinfilin 2 plays a role in the regulation of stereocilia elongation by restricting excessive elongation of the shorter row stereocilia thereby maintaining the mature staircase architecture of cochlear hair bundles.

\section{Introduction}

Inner ear sensory hair cells convert mechanical stimulation into electrical signals. This process of mechanoelectrical transduction happens at or near the tips of stereocilia, which are filamentous actin (F-actin)-filled protrusions of the hair cell's apical plasma membrane. Mechanosensitive ion channels are localized near the lower ends of the tip links that connect the tips of stereocilia to the sides of their next-tallest neighbor (Pickles et al., 1984; Beurg et al., 2009). The 50-100 F-actin-filled stereocilia comprising cochlear hair cell hair bundles are highly organized in three rows that are gradated in height. The staircase-like architecture of hair bundles is conserved among vertebrates (Tilney et al., 1992).

In mammals, cochlear hair bundle development can be divided into four general stages that have been described for the hamster: initial stereocilia sprouting, staircase initiation, ordered bundle formation, and elongation and pruning (Kaltenbach and Falzarano, 1994). Stereocilia first sprout as a microvilli tuft on

Received June 13, 2009; revised 0ct. 22, 2009; accepted 0ct. 24, 2009.

This work was supported by National Institute on Deafness and Other Communication Disorders Grants R01 DC4563 and P30 DC010363 (to S.H.), intramural funds 1 Z01-DC-000048-11 LMG (to T.B.F.), and, in part, when the work commenced at the Massachusetts Eye and Ear Infirmary in Boston, MA, by Training Grant T32 DC000020 support was continued by F31 DC009168 (to A.W.P.). We thank Dr. Pekka Lappalainen (Helsinki University) for providing antibodies to twinfilin and Andrew Guzzetta (Stanford) for expert help with mass spectrometry.

Correspondence should be addressed to Stefan Heller, Departments of Otolaryngology-Head \& Neck Surgery and Molecular \& Cellular Physiology, Stanford University School of Medicine, 801 Welch Road, Stanford, CA 94305-5739. E-mail: hellers@stanford.edu.

DOI:10.1523/JNEUROSCI.2782-09.2009

Copyright $\odot 2009$ Society for Neuroscience 0270-6474/09/2915083-06\$15.00/0 the apical surface of the hair cell. During initial staircase formation, stereocilia undergo a period of differential elongation, however, stereocilia rows are not well organized. The final phase consists of stereocilia elongating to their mature lengths, and resorption of excess short stereocilia/microvilli that are not a part of the final hair bundle structure.

The determining factor of stereocilia height is the length of its F-actin core. Because stereocilia bundle length varies very little at a given position along the cochlea, compared with neighboring hair cells, it is assumed that actin polymerization and depolymerization within stereocilia are tightly regulated (Tilney et al., 1992). Some stereociliary proteins such as the actin-crosslinker espin (Zheng et al., 2000; Salles et al., 2009), unconventional myosin XVa (Belyantseva et al., 2003a; Rzadzinska et al., 2004; Belyantseva et al., 2005), unconventional myosin VIIa (Rhodes et al., 2004; Prosser et al., 2008), and scaffolding protein whirlin (Belyantseva et al., 2003b; Mburu et al., 2003; Belyantseva et al., 2005; Delprat et al., 2005; Kikkawa et al., 2005) have been implicated in stereocilia length regulation. However, the molecules that directly regulate actin dynamics in stereocilia remain unknown.

Here, we show that the actin regulator twinfilin 2 specifically becomes localized at the tips of short- and middle-row cochlear stereocilia, but not in tall-row stereocilia. The onset of twinfilin 2 correlates with a period when tall-row stereocilia elongate substantially. In biochemical assays, twinfilin 2 displays a strong ability to cap actin filament barbed ends as well as an ability to sequester actin monomers (Vartiainen et al., 2003; Nevalainen et 

A MTHQTG IHAT
VDYDAFVLPL
Y A ATR ATVK K
EQELQQ I R I N
I Q L K LDLER E
ESVVF I Y S M P
A E L T A E F L Y D
$\begin{array}{llllllllll}T & E & L & R & D & F & F & A & K & A \\ L & D & E & Q & Q & P & C & Y & V & L \\ E & F & C & C & C & H & I & K & D & E \\ E & V & K & T & E & I & S & V & E & S \\ T & I & D & L & V & H & T & S & P & T \\ C & Y & K & C & S & I & K & E & R & M \\ E & V & H & P & K & Q & H & A & F & K\end{array}$
R N G S V R L I K V
Y R L D S Q N A Q C
$M F C T V K E D V S$
K HQT L Q C L A F
D I S DLPKR I P
L Y S SCKSR L
Q A F A K P K G P V

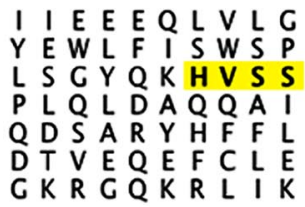
A HKE LAR R W D
DN S PVR LKML
C S A P A P L T A A
QT L K Q K K I N Y
$Y$ K H S HE C D Y L
I AKK I E I D D G
G PGENCEDS
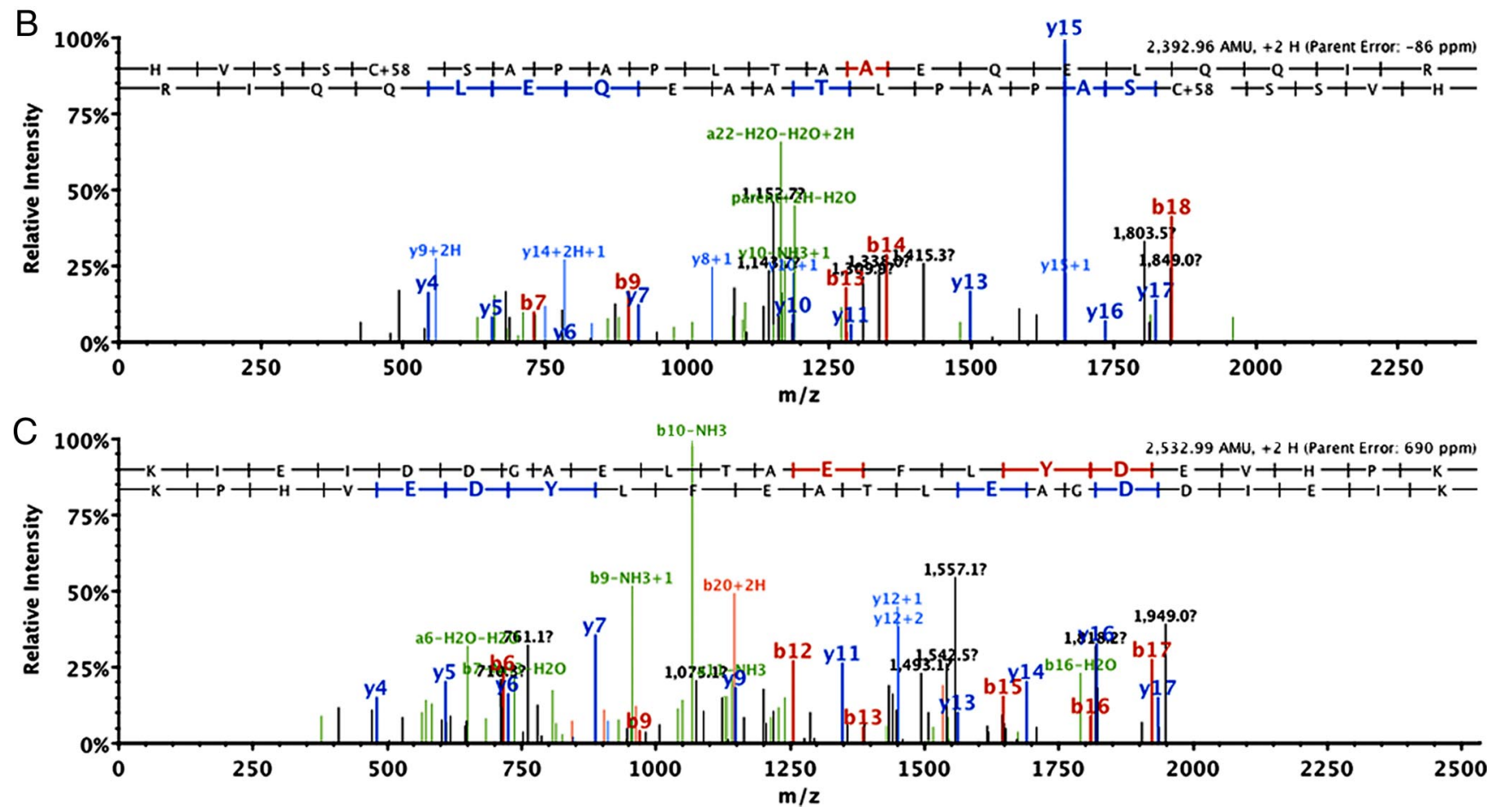

Figure 1. Identification of twinfilin 2 in the hair bundle. $\boldsymbol{A}$, Sequence of chicken twinfilin 2 with the identified peptides highlighted. Green highlight indicates an amino acid that was identified as being carboxymethylated. $\boldsymbol{B}, \boldsymbol{C}$, Mass spectra of identified peptide fragments for twinfilin 2 shown in $\boldsymbol{A}$. Identified fragments are indicated.

al., 2009). When we overexpressed twinfilin 2 in espin-transfected LLC-PK1/CL4 cells, we saw a significant reduction in microvilli lengths. Similarly, in cochlear hair cells, we found a significant reduction in the heights of the tallest row of stereocilia within the bundle. Our results suggest that twinfilin 2 regulates the length of the stereocilia F-actin core in developing and mature cochlear hair cells.

\section{Materials and Methods}

Antibodies, immunostainings, and clones. We obtained from Pekka Lappalainen (Helsinki University) two polyclonal antibodies, one recognizing only twinfilin 1 and another antibody recognizing both twinfilin 1 and 2 (twinfilin 1\&2) (Vartiainen et al., 2003). Localization of twinfilin 2 was performed using the twinfilin $1 \& 2$ antibody. The antibody that recognizes only twinfilin 1 did not show any detectable stereocilia tip staining but did stain Deiters' cell processes (supplemental Fig. S1, available at www.jneurosci.org as supplemental material). The twinfilin 1\&2 antibody shows twinfilin immunoreactivity at the tips of stereocilia of shorter rows, indicating that twinfilin 2 is localized to stereocilia tips (supplemental Fig. S1, available at www.jneurosci.org as supplemental material).

Whole-mount samples were fixed with $4 \%$ paraformaldehyde for $1 \mathrm{~h}$, blocked in PBT1 (0.1\% Triton X-100, 1\% BSA, 5\% heat-inactivated goat serum in PBS, pH 7.3) for $10 \mathrm{~min}$, and incubated overnight at $4^{\circ} \mathrm{C}$ with 1:200 anti-Twf1\&2 in PBT1. Samples were washed and incubated with Alexa 488 goat anti-rabbit antibody (Invitrogen) for $1 \mathrm{~h}$ followed by incubation in $0.4 \mu \mathrm{g} / \mathrm{ml}$ tetramethylrhodamine isothiocyanate (TRITC)conjugated phalloidin for $20 \mathrm{~min}$, washed, mounted, and imaged with a confocal microscope (LSM Pascal, Zeiss). Images were acquired using 1.4 NA oil-immersion objectives; stacks were analyzed with Volocity soft- ware (Improvision) for 3D length measurements, and Adobe Photoshop was used to assemble the figures.

Twinfilin 2 was expressed using a pcDNA3.1-based vector harboring an internal ribosome entry site (IRES) mCherry reporter. For gene gun experiments, twinfilin 2 was also cloned into pTracer EF/V5/HIS (Invitrogen), which has a dual promoter EGFP reporter.

Mass spectrometry. Chicken utricle hair bundles were isolated through a modified twist-off technique (Gillespie and Hudspeth, 1991). The main modification was that no "twisting" actually occurred; rather, we "ripped" the utricular macula away from the agarose gel in which the hair bundles remained embedded. Bundles were lysed with an SDS (2\% SDS, $147 \mathrm{~mm}$ Tris, and $0.51 \mathrm{~mm}$ EDTA, $\mathrm{pH}$ 8.5) solution and proteins were precipitated using $23 \%$ trichloroacetic acid. Protein was denatured in $8 \mathrm{~m}$ urea, carboxymethylated with $25 \mathrm{~mm}$ iodoacetic acid, and trypsinized with $1 \mu \mathrm{g}$ of modified trypsin (Promega). The peptides were purified from the solution using a Pepclean C-18 spin column (Thermo Fisher Scientific). Resulting peptides were analyzed by a modified version of the traditional MudPIT experiment by using a tetraphasic continuous column approach (Guzzetta and Chien, 2005). Scaffold (Proteome Software) was used to statistically analyze database search results.

Length measurements. Measurements were made on confocal Z-stacks taken with $0.4 \mu \mathrm{m}$ steps using Volocity software (Improvision). All length measurements were made in the apical $900 \mu \mathrm{m}$ of the cochlea of three animals per age $(n=3)$. ANOVA and $t$ tests were performed using Excel. For scanning electron microscopy measurements, cochleae were isolated from $\mathrm{BALB} / \mathrm{c}$ mice and fixed overnight at $4^{\circ} \mathrm{C}$ with $1 \%$ glutaraldehyde and 2\% PFA in $50 \mathrm{~mm} \mathrm{CaCl} 2$ and $20 \mathrm{~mm} \mathrm{MgCl} 2$ in $0.1 \mathrm{~m} \mathrm{HEPES}$ buffer, pH 7.4. Tissue was then treated for two $1 \mathrm{~h}$ cycles with $1 \%$ osmium 

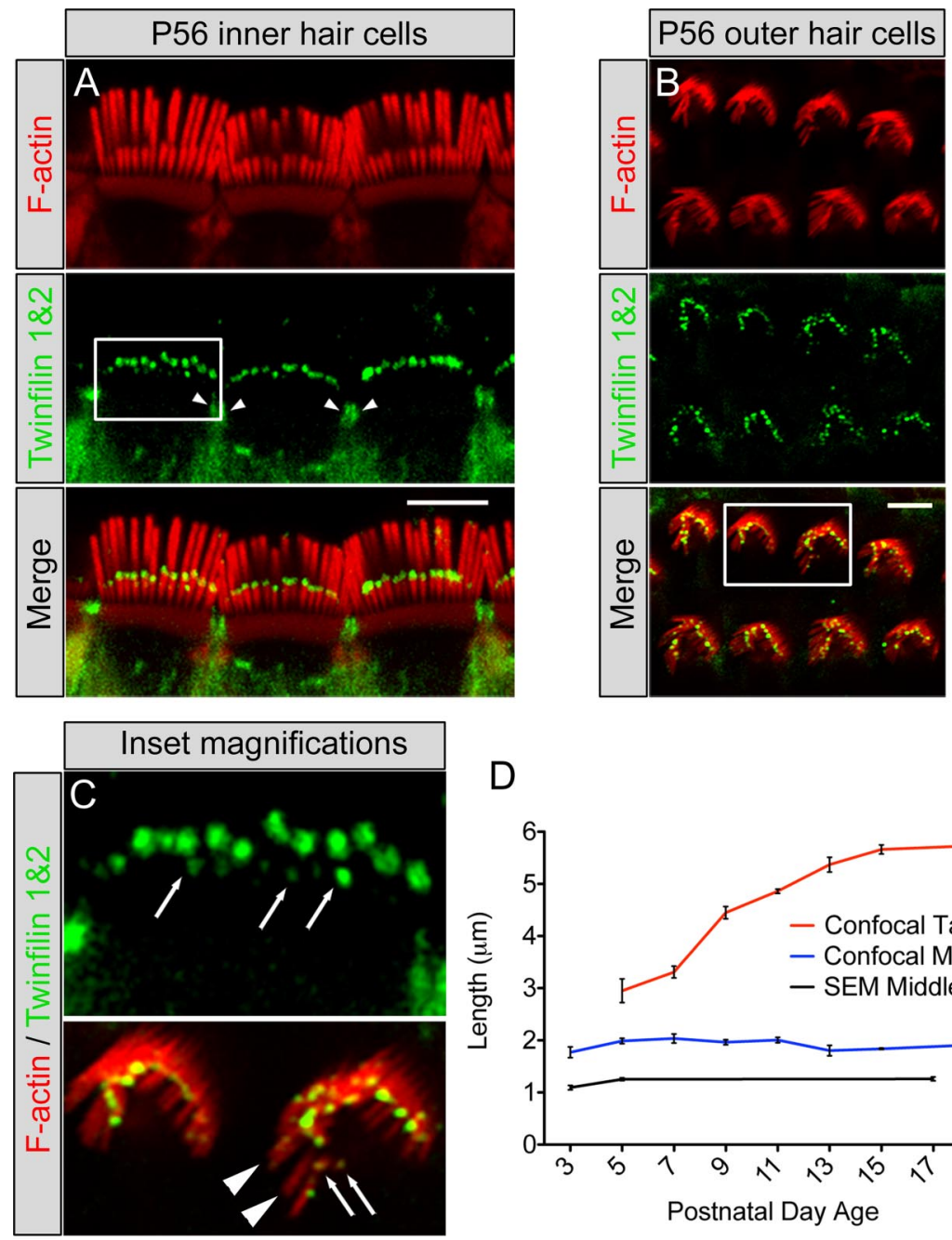

\section{$\mathrm{D}$}
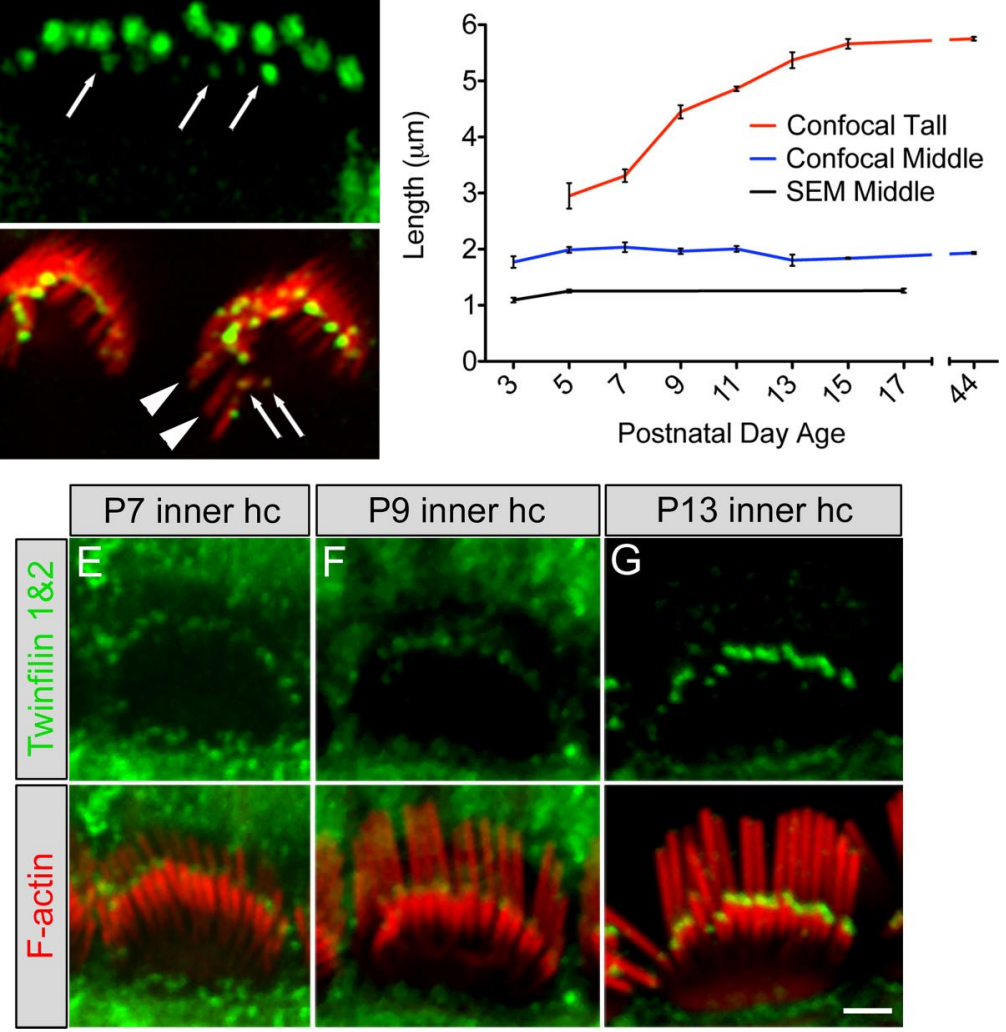

Figure 2. Twinfilin 2 localization in hair cell stereocilia and developmental characterization. $A, B$, Localization using a twinfilin $1 \& 2$ antibody (green) on P56 mouse cochlea showing tip staining of the middle and short rows of stereocilia in inner hair cells $(\boldsymbol{A})$ and outer hair cells $(\boldsymbol{B})$ as well as the pericuticular necklace region of inner hair cells (arrowheads). F-actin was labeled with TRITC-conjugated phalloidin (red). C, Top, Enlargement of the square in $\boldsymbol{A}$ showing the staining at the tips of short-row stereocilia in inner hair cells (arrows); bottom, enlargement of the square in $\boldsymbol{B}$ showing lack of staining at tips of tall-row stereocilia (arrowheads) and staining at the tips of short-row stereocilia (arrows). D, Inner hair cell stereocilia lengths for tall (red line) and middle (blue line) rows using confocal microscopy, and middle-row lengths (black line) determined with scanning electron microscopy (SEM) (mean $\pm S D, n=3$ ). Scanning electron microscopy-measured lengths were consistently shorter than confocal-measured lengths, likely due to the dehydration steps in tissue processing. $\boldsymbol{E}-\boldsymbol{G}$, Developmental expression of twinfilin 2 (green) shows increasing labeling intensity with age from $P 7(\boldsymbol{E})$ to $P 9(\boldsymbol{F})$ to P13 (G). Scale bars: $=\boldsymbol{A}, \boldsymbol{B} ; 5 \mu \mathrm{m} ; \boldsymbol{E}-\boldsymbol{G}, 2 \mu \mathrm{m}$. tetroxide followed by $1 \%$ tannic acid for $1 \mathrm{~h}$, dehydrated in an ethanol gradient, critical point dried (Autosamdri 814; Tousimis), and imaged with a Hitachi S-3400N scanning electron microscope. Length measurements were performed with Volocity with at least three animals. Graphs were made using Prism software (GraphPad).

CL4 cells. CL4 cells (ATCC CL-101) stably expressing rat espin $\Delta \mathrm{N} 338$ (Loomis et al., 2003) fused to EGFP were transfected using the Amaxa Nucleofector using solution L and program T-020. Three to five days later, cells were visualized with $100 \times 1.4 \mathrm{NA}$ objective using a spinning disk confocal microscope (Yokogawa/ Zeiss). Sixteen microvilli were measured for each transfected cell and 16 microvilli were measured for the neighboring untransfected cells. The averages were used for analysis using Prism software (GraphPad).

Hair cell transfections. Apical and middle turn pieces of P3-P4 organs of Corti from C57BL/6 mice were attached to glass-bottomed Petri dishes (MatTek) coated with CellTak (Collaborative Biomedical Products) and maintained at $37^{\circ} \mathrm{C}$ and $5 \% \mathrm{CO}_{2}$ in DMEM supplemented with $7 \%$ FBS for $1 \mathrm{~d}$. Cultures were transfected using a Helios gene gun (Bio-Rad) as described previously (Belyantseva, 2009). Gold particles of $1.0 \mu \mathrm{m}$ in diameter were coated with plasmid DNA at a ratio of $2 \mu \mathrm{g}$ of DNA to $1 \mathrm{mg}$ of particles and precipitated onto the inner wall of Tefzel tubing, which was cut into individual cartridges containing $\approx 1 \mu \mathrm{g}$ of plasmid DNA. The external ring of the standard barrel of the Bio-Rad gene gun was positioned at the bottom of a culture dish in such a way that the organ of Corti explant appeared in the center of the barrel ring. Samples were bombarded with the gold particles from one cartridge per culture by using 120 psi of helium. After an additional 1-2 d, samples were fixed with $4 \%$ paraformaldehyde, stained with TRITC-conjugated phalloidin, and observed by using a Zeiss LSM710 confocal microscope equipped with $63 \times 1.4 \mathrm{NA}$ and $100 \times 1.4 \mathrm{NA}$ objectives.

\section{Results}

Twinfilin 2 is associated with the tips of stereocilia

To identify novel stereociliary proteins, we performed a mass-spectrometry-based proteomics analysis of chicken utricle hair bundle proteins. Among several proteins identified, we found two tryptic fragments of twinfilin 2 with $>95 \%$ confidence (Fig. 1). Because chicken and mammalian twinfilin 2 have high homology (supplemental Fig. S2, available at www.jneurosci.org as supplemental material), we decided to perform the analyses of twinfilin 2 expression and its potential function in the mouse. Further, because stereocilia of cochlear hair cells are uniformly organized and thick enough to be clearly resolved with light microscopy, we chose to focus 
our analysis on the murine organ of Corti. When we localized the protein in adult mouse cochlear hair cells, we found strong immunolabeling of twinfilin 2 at the tips of the middle and short rows of stereocilia (Fig. $2 A-C$ ). The protein might be present in tall stereocilia at very low levels, but the labeling was too faint for reliable imaging. This localization is consistent with a role of twinfilin 2 in capping the barbed ends of stereocilia actin filaments in the middle and short rows of stereocilia, which points to potential differences in regulation of actin dynamics in the shorter two rows of stereocilia compared with the tall row, in which twinfilin 2 is present at very low levels, if at all. The localization pattern is also consistent between both inner and outer hair cells indicating a common mechanism of barbed end capping and length control between these hair cell types (Fig. $2 B, C$ ).

Onset of twinfilin 2 expression correlates with differential elongation of stereocilia To determine a potential correlation between stereocilia growth and twinfilin 2 expression, we initially considered possible roles for twinfilin 2 in hair bundle development and neonatal hair bundle maturation and maintenance. At postnatal day 0 , twinfilin 2 was not detectable in stereocilia, which led us to assume that twinfilin 2 is not present during initial hair bundle formation and growth, and consequently, not involved in initial stair-

case formation. Twinfilin 2 expression was first detectable, faintly, at the tips of middle row of stereocilia at postnatal day 5 (data not shown). At postnatal day 7, the protein was evident more robustly, and its expression gradually increased until postnatal day 13, when labeling intensities were comparable to the adult (Fig. $2 E-G$ ). This time period likely corresponds to the final phase of elongation and pruning that has been observed in hamster inner hair cells of the apical cochlea, leading to establishment of the mature staircase architecture (Kaltenbach et al., 1994).

To correlate twinfilin 2 expression with murine postnatal hair bundle development, we measured inner hair cell stereocilia lengths in the cochlear apical turn. To measure mouse hair cell stereocilia length changes, we used quantitative 3-dimensional image data analyses of confocal image stacks obtained by collecting consecutive optical sections of inner hair cells (supplemental Movie, available at www.jneurosci.org as supplemental material). We found that, after the initial staircase has been established, tall stereocilia exhibit a final burst of elongation between P7-P13, in which their length increased from $3.31 \pm 0.11 \mu \mathrm{m}$ (mean $\pm \mathrm{SD}$, $n=3$ ) to $5.37 \pm 0.14 \mu \mathrm{m}$ (mean $\pm \mathrm{SD}, n=3$ ) and stereocilia bundles acquire a mature staircase architecture (Fig. $2 \mathrm{D}$ ). In contrast, the middle rows of stereocilia do not show elongation between P5 and P44, and they maintain a length of $\sim 2 \mu \mathrm{m}$ (P5 $1.99 \pm 0.05 \mu \mathrm{m} ; \mathrm{P} 441.93 \pm 0.02 \mu \mathrm{m})$. Moreover, when measured at P3, the length of the middle row was $1.77 \pm 0.10 \mu \mathrm{m}$ (mean $\pm \mathrm{SD}, n=3$ ), in agreement with the onset of twinfilin 2 expression and with a potential role of twinfilin 2 in stalling the elongation of middle-row stereocilia. Because P3 middle-row stereocilia cannot be as easily resolved with confocal microscopy as they can at P5, we decided to further confirm these observations with scanning electron microscopy. Our analysis confirmed growth of the middle row of stereocilia between P3 and P5 $[1.09 \pm 0.04 \mu \mathrm{m}$ at $\mathrm{P} 3$ versus $1.25 \pm 0.03 \mu \mathrm{m}$ at $\mathrm{P} 5$; mean $\pm \mathrm{SD}$, $n=3$ (P3), $n=4$ (P5)], and that the middle-row stereocilia do not elongate between P5 and P17 (1.26 $\pm 0.04 \mu \mathrm{m}$ at P17; mean $\pm \mathrm{SD}, n=4)$ (Fig. 2D).

Twinfilin 2 expression leads to shorter microvilli in CL4 cells If twinfilin 2 affects the length of actin filaments in stereocilia, then we expect that it would also have this function in CL4 cells, which have been used as an in vitro model system to examine parallel F-actin bundles (Loomis et al., 2003). When we stably transfected CL4 cells with the stereociliary actin bundling protein espin (Zheng et al., 2000) they formed prolonged microvilli of average lengths of $3.58 \pm 0.31 \mu \mathrm{m}$ (mean \pm SEM, $n=6$ cells) (Fig. $3 A, B$ ). When we expressed twinfilin 2 along with espin, the CL4 microvilli were significantly shorter $(2.56 \pm 0.07 \mu \mathrm{m}$; mean \pm SEM, $n=6$ cells; $p<0.01$ one-tailed $t$ test) (Fig. $3 A-C$ ). Control transfected cells did not display significant changes in microvilli lengths (untransfected: $2.89 \pm 0.40 \mu \mathrm{m}$; transfected: $2.94 \pm 0.40 \mu \mathrm{m}$; mean $\pm \mathrm{SEM}, n=10$ cells) (Fig. $3 C, D$ ). These numbers calculate to a significant length reduction of microvilli of twinfilin 2 transfected cells $(26.11 \pm 5.90 \%$; mean \pm SEM, $n=$ 6 cells) when compared with control transfections $(0.09 \pm 6.1 \%$; mean \pm SEM, $n=10$ cells; $p<0.01$ one-tailed $t$ test $)$. Based on 
these observations, we conclude that overexpression of twinfilin 2 in CL4 cells results in a shorter length of espin-bundled actin filaments when compared with controls.

Twinfilin 2 overexpression leads to stunted stereocilia

The effect of twinfilin 2 expression on CL4 cell microvilli prompted us to test its function in native hair cells. A first indication that the presence of twinfilin 2 at stereociliary tips affects their elongation came from analysis of whirler and shaker 2 hair cells, which display shortened stereocilia (Holme et al., 2002; Belyantseva et al., 2005). Twinfilin 2 immunoreactivity in these mice is associated with the tips of all short stereocilia, indicating a potential role in suppressing F-actin-based elongation (supplemental Fig. S3, available at www.jneurosci.org as supplemental material). This observation led us to coexpress twinfilin 2 in postnatal day 3-4 cochlear inner hair cells using a biolistic particle delivery system (Belyantseva, 2009). We identified transfected cells by means of EGFP expression (Fig. $4 A, B$ ). We found that hair cells overexpressing twinfilin 2 displayed significantly shorter tall stereocilia when compared with their nontransfected neighbors (Fig. $4 A, C$ ). The tall-row stereocilia were shorter on average by $11.8 \pm 2.4 \%(n=9)$. Cells that were transfected with expression vectors for EGFP did not display significant stereocilia length differences when compared with their nontransfected neighbors $(-1.7 \pm 1.9 \% ; n=8$ ) (Fig. $4 B, C$ ). It is interesting that the tall stereocilia are affected by twinfilin 2 overexpression, which could be due to immature gate-keeping at the stereocilia base, absence of a specific transport mechanism in young hair cells, or simply due to the overexpression of twinfilin 2. Because only tall stereocilia grow during the period investigated, it is not surprising that only the tall rows of stereocilia are affected by twinfilin 2 overexpression, resulting in the difference in transfected stereocilia heights versus nontransfected heights.

\section{Discussion}

In this study, we identified a novel stereociliary protein, twinfilin 2. Immunocytochemically, twinfilin 2 becomes detectable at the tips of middle- and short-row cochlear stereocilia at the beginning of a growth phase of the tall stereocilia row that starts around P5. Overexpression of twinfilin 2 in CL4 cells and in cochlear hair cells both results in shorter microvilli and stereocilia, respectively. These findings point to a strong ability of twinfilin to suppress the growth of F-actin and/or to modulate F-actin dynamics at the barbed ends. The potential function and localization of twinfilin 2 at the tips of the middle and short rows of stereocilia may point to a role in precisely maintaining the length of these stereocilia in mature hair cells.

Our measurements of stereocilia length dynamics revealed that in mice, the tall stereocilia row of cochlear inner hair cells elongates by $>60 \%$ from $\mathrm{P} 7$ to P13. Overt expression of twinfilin 2 was neither detectable in tall stereocilia during this time period nor in the adult. The middle and short rows of stereocilia, in which twinfilin 2 becomes coincidently upregulated, do not grow in length during this period when twinfilin 2 immunoreactivity at the tips reaches the intensity observed in the adult. The spatial and temporal expression of twinfilin 2 is in agreement with a role of preventing further elongation of the short and middle stereocilia rows in neonatal hair bundle maturation during the burst of growth that we observe from P5 to P15. The strong twinfilin 2 expression at the tips of short- and middle-row stereocilia is maintained into adulthood, which suggests that F-actin growth control at the barbed ends of these stereocilia remains important in fully developed hair cells.
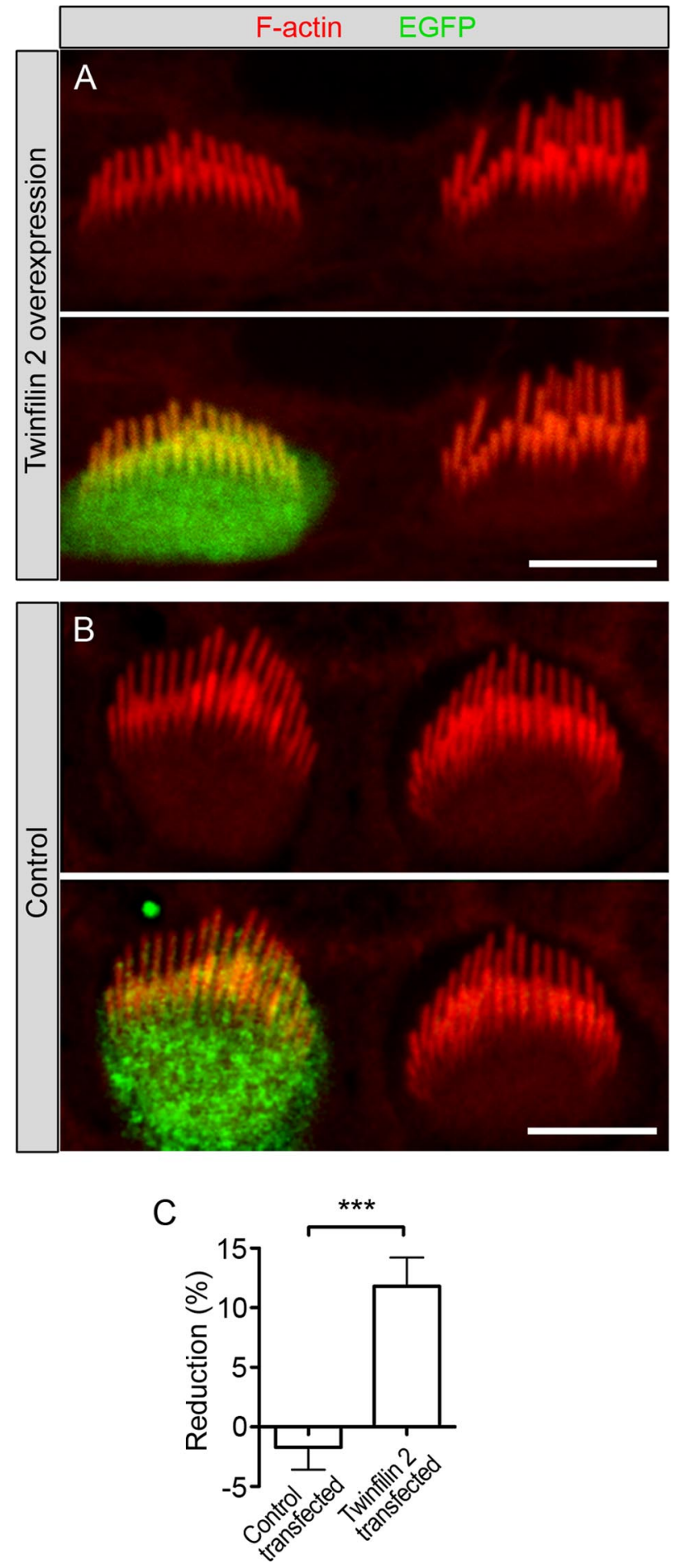

Figure 4. Effects of overexpression of twinfilin 2 on cochlear hair cells. $A$, Hair cells were transfected with a bicistronic expression vector for twinfilin 2 and EGFP (green). Shown is a representative pair of transfected and untransfected inner hair cells. F-actin was visualized with TRITC-conjugated phalloidin (red). Cochleae were dissected at P3-P4 and transfected after $1 \mathrm{~d}$ in vitro (DIV), and images were taken at 2-3 DIV. B, Control hair cell transfected with a vector expressing only EGFP (green). C, Individual tall stereocilia lengths were averaged for each transfected hair cell and its untransfected neighbors and average length reductions are shown (mean \pm SEM, $n=9$ for twinfilin $2, n=8$ for controls). Statistical analysis with an unpaired one-tailed $t$ test yields a significant change of $p<0.0005$. Scale bars: $5 \mu \mathrm{m}$. 
We hypothesize that barbed end capping of actin filaments is the mechanism by which twinfilin 2 affects F-actin dynamics, but we cannot rule out an effect mediated by local actin monomer sequestration, which is probably unavoidable in overexpression studies. The native expression of twinfilin 2 at the barbed ends of short- and middle-row stereocilia could be the consequence of a specific transport mechanism or specific binding sites at this particular location. Myosin VIIa appears to be a binding partner of twinfilin 2 as a recent study reveals that myosin VIIa is necessary for tip localization of twinfilin 2 and that both proteins interact in vivo (Rzadzinska et al., 2009).

In summary, twinfilin 2 is an actin regulator at a highly interesting subcellular location at the tips of short- and middle-row stereocilia, where we propose that the protein's function is to govern growth of actin filaments. The presence of twinfilin 2 in adult stereocilia suggests that it might play a role in controlling the mature length of the middle and short rows of stereocilia. This length maintenance is crucial for proper tip link angle and tension, which are important for hair cell mechanosensitivity and function of the transduction machinery.

\section{References}

Belyantseva IA (2009) Helios Gene Gun-mediated transfection of the inner ear sensory epithelium. Methods Mol Biol 493:103-123.

Belyantseva IA, Boger ET, Friedman TB (2003a) Myosin XVa localizes to the tips of inner ear sensory cell stereocilia and is essential for staircase formation of the hair bundle. Proc Natl Acad Sci U S A 100:13958-13963.

Belyantseva IA, Labay V, Boger ET, Griffith AJ, Friedman TB (2003b) Stereocilia: the long and the short of it. Trends Mol Med 9:458-461.

Belyantseva IA, Boger ET, Naz S, Frolenkov GI, Sellers JR, Ahmed ZM, Griffith AJ, Friedman TB (2005) Myosin-XVa is required for tip localization of whirlin and differential elongation of hair-cell stereocilia. Nat Cell Biol 7:148-156.

Beurg M, Fettiplace R, Nam JH, Ricci AJ (2009) Localization of inner hair cell mechanotransducer channels using high-speed calcium imaging. Nat Neurosci 12:553-558.

Delprat B, Michel V, Goodyear R, Yamasaki Y, Michalski N, El-Amraoui A, Perfettini I, Legrain P, Richardson G, Hardelin JP, Petit C (2005) Myo$\sin \mathrm{XVa}$ and whirlin, two deafness gene products required for hair bundle growth, are located at the stereocilia tips and interact directly. Hum Mol Genet 14:401-410.

Gillespie PG, Hudspeth AJ (1991) High-purity isolation of bullfrog hair bundles and subcellular and topological localization of constituent proteins. J Cell Biol 112:625-640.

Guzzetta AW, Chien AS (2005) A double-vented tetraphasic continuous column approach to MuDPIT analysis on long capillary columns demonstrates superior proteomic coverage. J Proteome Res 4:2412-2419.

Holme RH, Kiernan BW, Brown SD, Steel KP (2002) Elongation of hair cell stereocilia is defective in the mouse mutant whirler. J Comp Neurol 450:94-102.
Kaltenbach JA, Falzarano PR (1994) Postnatal development of the hamster cochlea. I. Growth of hair cells and the organ of Corti. J Comp Neurol 340:87-97.

Kaltenbach JA, Falzarano PR, Simpson TH (1994) Postnatal development of the hamster cochlea. II. Growth and differentiation of stereocilia bundles. J Comp Neurol 350:187-198.

Kikkawa Y, Mburu P, Morse S, Kominami R, Townsend S, Brown SD (2005) Mutant analysis reveals whirlin as a dynamic organizer in the growing hair cell stereocilium. Hum Mol Genet 14:391-400.

Loomis PA, Zheng L, Sekerková G, Changyaleket B, Mugnaini E, Bartles JR (2003) Espin cross-links cause the elongation of microvillus-type parallel actin bundles in vivo. J Cell Biol 163:1045-1055.

Mburu P, Mustapha M, Varela A, Weil D, El-Amraoui A, Holme RH, Rump A, Hardisty RE, Blanchard S, Coimbra RS, Perfettini I, Parkinson N, Mallon AM, Glenister P, Rogers MJ, Paige AJ, Moir L, Clay J, Rosenthal A, Liu XZ, et al (2003) Defects in whirlin, a PDZ domain molecule involved in stereocilia elongation, cause deafness in the whirler mouse and families with DFNB31. Nat Genet 34:421-428.

Nevalainen EM, Skwarek-Maruszewska A, Braun A, Moser M, Lappalainen P (2009) Two biochemically distinct and tissue-specific twinfilin isoforms are generated from the mouse Twf2 gene by alternative promoter usage. Biochem J 417:593-600.

Pickles JO, Comis SD, Osborne MP (1984) Cross-links between stereocilia in the guinea pig organ of Corti, and their possible relation to sensory transduction. Hear Res 15:103-112.

Prosser HM, Rzadzinska AK, Steel KP, Bradley A (2008) Mosaic complementation demonstrates a regulatory role for myosin VIIa in actin dynamics of stereocilia. Mol Cell Biol 28:1702-1712.

Rhodes CR, Hertzano R, Fuchs H, Bell RE, de Angelis MH, Steel KP, Avraham KB (2004) A Myo7a mutation cosegregates with stereocilia defects and low-frequency hearing impairment. Mamm Genome 15:686-697.

Rzadzinska AK, Schneider ME, Davies C, Riordan GP, Kachar B (2004) An actin molecular treadmill and myosins maintain stereocilia functional architecture and self-renewal. J Cell Biol 164:887-897.

Rzadzinska AK, Nevalainen EM, Prosser HM, Lappalainen P, Steel KP (2009) MyosinVIIa interacts with Twinfilin-2 at the tips of mechanosensory stereocilia in the inner ear. PLoS One 4:e7097.

Salles FT, Merritt RC Jr, Manor U, Dougherty GW, Sousa AD, Moore JE, Yengo CM, Dosé AC, Kachar B (2009) Myosin IIIa boosts elongation of stereocilia by transporting espin 1 to the plus ends of actin filaments. Nat Cell Biol 11:443-450.

Tilney LG, Tilney MS, DeRosier DJ (1992) Actin filaments, stereocilia, and hair cells: how cells count and measure. Annu Rev Cell Biol 8:257-274.

Vartiainen MK, Sarkkinen EM, Matilainen T, Salminen M, Lappalainen P (2003) Mammals have two twinfilin isoforms whose subcellular localizations and tissue distributions are differentially regulated. J Biol Chem 278:34347-34355.

Zheng L, Sekerková G, Vranich K, Tilney LG, Mugnaini E, Bartles JR (2000) The deaf jerker mouse has a mutation in the gene encoding the espin actin-bundling proteins of hair cell stereocilia and lacks espins. Cell 102: $377-385$. 